\title{
Nanoparticles for Local Drug Delivery to the Oral Mucosa: Proof of Principle Studies
}

\author{
Andrew S. Holpuch • Garrett J. Hummel $•$ Meng Tong $•$ Garrett A. Seghi • Ping Pei • Ping Ma $\bullet$ Russell J. Mumper $\bullet$ Susan R. Mallery
}

Received: 18 February 2010 / Accepted: 5 March 2010 / Published online: 31 March 2010

(C) The Author(s) 2010. This article is published with open access at Springerlink.com

\begin{abstract}
Purpose To determine if solid lipid nanoparticles represent a viable strategy for local delivery of poorly water soluble and unstable chemopreventive compounds to human oral tissues.

Methods Nanoparticle uptake and compound retention evaluations employed monolayer-cultured human oral squamous cell carcinoma (OSCC) cell lines and normal human oral mucosal explants. Feasibility of nanoparticle delivery was also evaluated with respect to the presence of phase-III efflux transporters in normal oral mucosal tissue and OSCC tissues.

Results Functional uptake assays confirmed significantly greater internalization of nanoparticle-delivered fluorescent probe relative to free-fluorescent probe delivery, while concurrently demonstrating nanoparticle uptake rate differences among the OSCC cell lines and the phagocytic control human monocyte cell line. Mucosal explants exhibited nanoparticle penetration and internalization in the spinous and basal epithelial layers
\end{abstract}

A. S. Holpuch • G. J. Hummel • M. Tong • G. A. Seghi • P. Pei •

S. R. Mallery

Division of Oral and Maxillofacial Surgery, Pathology \& Anesthesiology,

College of Dentistry, The Ohio State University,

Columbus, Ohio, USA

P. Ma.R. J. Mumper

Division of Molecular Pharmaceutics, UNC Eshelman School

of Pharmacy, Center for Nanotechnology in Drug Delivery,

University of North Carolina at Chapel Hill,

Chapel Hill, North Carolina, USA

\section{S. R. Mallery}

James Cancer Hospital and Solove Research Institute,

The Ohio State University,

Columbus, Ohio, USA

S. R. Mallery $(\square)$

2191B Postle Hall, 305 West I2th Avenue,

Columbus, Ohio 43210, USA

e-mail: mallery. I@osu.edu
(7/10 specimens), and also exhibited the presence of the phase-III efflux transporters multidrug resistance-associated protein I (MRPI) and breast cancer resistance protein (BCRP). Conclusions These data confirm nanoparticle internalization by OSCC cells and support the premise that nanoparticlebased delivery provides higher final intracellular levels relative to bolus administration. Furthermore, the penetration and subsequent internalization of nanoparticles within the proliferating basal layer cells demonstrates the feasibility of nanoparticle formulations for local delivery and stabilization of oral chemopreventive compounds.

KEY WORDS efflux transporter - local delivery - mucosal explants · nanoparticles $\cdot$ oral chemoprevention

$\begin{array}{ll}\text { ABBREVIATIONS } \\ \mu g & \text { microgram } \\ \mu \mathrm{I} & \text { microliter } \\ \mu \mathrm{M} & \text { micromolar } \\ \text { BCRP } & \text { breast cancer resistance protein } \\ \text { BODIPY-NPs } & \text { BODIPY FL } \mathrm{C}_{\text {I2-nanoparticles }} \\ \text { COX-2 } & \text { cyclooxygenase 2 } \\ \text { FBR } & \text { freeze-dried black raspberry } \\ \text { FluoSpheres } & \text { biotin-coated yellow-green } 200 \mathrm{~nm} \\ & \text { FluoSpheres }{ }^{R} \\ \text { free-IDA } & \text { free idarubicin } \\ \text { gm } & \text { gram } \\ \text { IDA-NPs } & \text { idarubicin nanoparticles } \\ \text { mg } & \text { milligram } \\ \text { ml } & \text { milliliter } \\ \text { MRPI } & \text { multidrug resistance-associated protein I } \\ \text { nm } & \text { nanometer } \\ \text { nM } & \text { nanomolar } \\ \text { OSCC } & \text { oral squamous cell carcinoma } \\ \text { P-gP } & \text { P-glycoprotein }\end{array}$




\section{SLN solid lipid nanoparticle \\ TFC thin-film composite}

\section{INTRODUCTION}

Due to their visibly accessible location and characterized progression from oral dysplastic lesions to oral squamous cell carcinoma, premalignant oral epithelial lesions present an ideal opportunity for chemoprevention. Despite these obvious clinical advantages, results from previously conducted oral cancer chemoprevention trials have generally been disappointing (1-8). The majority of these previous clinical trials relied on systemic agent administration and did not determine whether or not therapeutically relevant chemopreventive compound levels were achieved at the treatment site (1-5). It is therefore impossible to distinguish whether these negative data reflect the use of ineffective chemopreventive compounds or lack of compound bioavailability at the target tissue (9). In contrast to systemic administration, local delivery of therapeutic compounds introduces the potential to maximize local effects while negating systemic consequences.

Our laboratories recently completed a Phase I/II clinical trial to evaluate the effects of a topically applied $10 \%$ freeze-dried black raspberry (FBR) aqueous gel on premalignant oral lesions $(10,11)$. Topical FBR gel application (2 gm daily, applied as 0.5 gm q.i.d. for 6 weeks) effectively delivered therapeutically relevant levels of chemopreventive compounds, i.e., anthocyanins, to the oral target tissues (12). Treatment resulted in histopathologic regression, significant reduction in loss of heterozygosity indices at tumor-suppressor-gene-associated loci, decrease in lesionalassociated angiogenesis, and significant reduction of cyclooxygenase 2 (COX-2) protein in treated dysplastic oral epithelium (10,11). Not all trial participants, however, derived comparable chemopreventive benefits (10,11). Consequently, we are currently investigating the prospect of combining additional compounds with FBR treatment, e.g., fenretinide, to enhance overall clinical responsiveness. Notably, levels of beta-carotene, a vitamin A precursor, are negligible within the FBR formulations (13).

By virtue of its proapoptotic and differentiation-inducing effects, the synthetic vitamin A analog, N-(4-hydroxyphenyl) retinamide (fenretinide), is a promising chemopreventive compound for premalignant epithelial lesions $(14,15)$. While fenretinide provides the antineoplastic effects of vitamin A, it also demonstrates a decreased resistance-induction and toxicity profile (14). Furthermore, while a high fenretinide concentration $(10 \mu \mathrm{M})$ induced apoptosis through a receptor-independent pathway, a low fenretinide concentration $(1 \mu \mathrm{M})$ promoted epithelial differentiation through a receptor-dependent mechanism (15). Fenretinide's receptorindependent induction of apoptosis presents the potential for long-term efficacy due to the lack of acquired receptorresistance. This prospect is particularly appealing provided that oral cavity chemoprevention will likely entail sustainedduration treatment. A recent clinical trial, however, administered systemic high-dose fenretinide, which resulted in minor toxicities and minimal histopathological improvement within the enrolled patients (5). This fenretinide study did not determine fenretinide levels in the target tissues (5). While the oral cavity is richly vascularized, the surface epithelium itself is avascular. Consequently, topical delivery of chemopreventive compounds will likely provide therapeutically relevant concentrations in the target tissue, i.e., epithelial layers, without relying on perfusion from the underlying vasculature and minimizing the toxicities associated with systemic exposure.

Based on their complementary mechanisms of action (i.e., FBR compounds exhibit strong antioxidant and antiinflammatory properties, and fenretinide induces apoptosis and differentiation), there is the prospect for inter-agent additive or synergistic chemopreventive effects with concurrent or sequential administration of FBR and fenretinide. Fenretinide, however, is poorly water soluble and prone to hydrolysis. Thus, it may be an ideal candidate for the entrapment in nanoparticles which serve both to enhance the apparent solubility and protect the drug from an aqueous environment (16).

Prior to formulation development and evaluation of solid lipid nanoparticles containing fenretinide, it was first necessary to establish the feasibility of using nanoparticles for local drug delivery to the oral mucosa. In these proof-of-principle studies, two types of nanoparticles were studied: solid lipid nanoparticles (SLN) incorporating either idarubicin or BODIPY ${ }^{\circledR}$ $\mathrm{FL} \mathrm{C}_{12}$ as model fluorescent probes and polystyrene nanoparticles (FluoSpheres $\left.{ }^{\circledR}\right)$. Although human oral mucosa contains cells with established phagocytic abilities, e.g., Langerhans cells and endothelial cells, questions remain regarding the capacity for oral epithelial cell nanoparticle internalization, particularly with regard to the intact stratified squamous oral epithelium. Our data, which show that monolayer human oral squamous cell carcinoma (OSCG) cells internalize nanoparticles and confirm that nanoparticles penetrate to the basal and superficial underlying connective tissue layers of intact normal oral epithelium, establish the prospect for nanoparticle formulation use in a local oral cancer chemoprevention strategy.

\section{MATERIALS AND METHODS}

\section{Materials}

Cell culture medium: Dulbecco's modified Eagle's medium and Hams F12 medium (DMEM/F12), RPMI 1640, fetal 
bovine serum (FBS), and gentamicin were purchased from GIBCO ${ }^{\circledR}$ (Grand Island, NY, USA). Eagle's Minimum Essential Medium (EMEM) was purchased from American Type Cell Culture (ATCG, Manassas, VA, USA). BODIPY® FL $\mathrm{C}_{12}$ and 4',6-diamidino-2-phenylindole (DAPI) were supplied by Invitrogen (Carlsbad, CA, USA). Biotin-coated yellow-green $200 \mathrm{~nm}$ FluoSpheres ${ }^{\circledR}$ and insulin from bovine pancreas were purchased from Sigma-Aldrich (Saint Louis, MO, USA). Vectashield mounting medium, Vectastain ABC reagent, $\mathrm{DAB}$ substrate, and biotinylated horse anti-mouse secondary antibody were obtained from Vector Laboratories (Burlingame, CA, USA). E-cadherin monoclonal antibody, Breast Cancer Resistance Protein (BCRP) monoclonal antibody [BXP-21], P-glycoprotein (P-gp) monoclonal antibody [C219 and JSB-1], and Texas Red anti-mouse secondary polyclonal antibody were purchased from Abcam (Cambridge, MA, USA). Multidrug resistanceassociated protein 1 (MRP1) monoclonal antibody [QCRL-1], $\beta$-actin monoclonal antibody, goat anti-mouse IgG-HRP, donkey anti-goat IgG-HRP, rat liver extract, and Blotto non-fat dry milk were obtained from Santa Cruz Biotechnology® (Santa Cruz, CA, USA). Mammalian protein extraction reagent (M-PER) was obtained from Pierce Protein Research Products (Thermo Fisher Scientific, Rockford, IL, USA). ECL plus Western blotting detection system was obtained from Amersham GE Healthcare Life Sciences (Buckinghamshire, UK). CL-Xposure films were obtained from Kodak (Rochester, NY, USA). Immun-Blot Polyvinylidene Fluoride (PVDF) Membranes were obtained from Bio-Rad Life Science Research (Hercules, CA, USA). FIBRACOL-Plus sponges were obtained from Johnson and Johnson (Somerville, NJ, USA).

\section{Cell Culture}

Four human cell lines derived from squamous cell carcinomas of the tongue (SCC4 [CRL-1624], SCC9 [CRL-1629], SCG15 [CRL-1623], and SCC25 [CRL-1628]), MCF7 human breast adenocarincoma cells [HTB-22], HCT-15 human colorectal adenocarcinoma cells [CCL-225], and U-937 human monocytes [CRL-1593.2] were obtained from American Type Cell Culture. Previous studies in our laboratory have confirmed that the four human oral squamous cell carcinoma cell lines retain features of intact oral mucosa inclusive of functional Phase I and II carcinogen metabolizing enzymes, inducible nitric oxide synthase and cyclooxygenase-2 (COX-2) enzymes, and a responsive thiolredox status (17-19). Oral squamous cell carcinoma (OSCG) cells were cultured in DMEM/F12 medium supplemented with $10 \%$ heat-inactivated $\mathrm{FBS}$ at $37^{\circ} \mathrm{C}, 5 \% \mathrm{CO}_{2}$. MCF7 cells were cultured in EMEM supplemented with $0.01 \mathrm{mg} / \mathrm{ml}$ bovine insulin and $10 \%$ heat-inactivated FBS at $37^{\circ} \mathrm{C}, 5 \%$ $\mathrm{CO}_{2}$. HCT-15 cells and U-937 monocytes were cultured in
RPMI-1640 medium supplemented with $10 \%$ heatinactivated $\mathrm{FBS}$ at $37^{\circ} \mathrm{C}, 5 \% \mathrm{CO}_{2}$.

\section{Human Oral Tissue Collection}

Twenty-five normal human oral mucosal tissues were obtained from patients undergoing elective oral surgical procedures. Ten specimens were used for evaluation of nanoparticle penetration, and 15 specimens were used for Western blot and immunohistochemistry analysis of phaseIII efflux transporter expression. Furthermore, five human OSCG specimens, which were obtained from the Ohio State University Comprehensive Cancer Center Tissue Procurement Service, were used for immunohistochemistry analysis of phase-III efflux enzyme expression. Human subject participation was in accordance with the Ohio State University Institutional Review Board approval and followed the tenets of the Declaration of Helsinki 1964.

\section{Formulation of Idarubicin and BODIPY FL $\mathbf{C}_{12}$ Solid Lipid Nanoparticles}

The idarubicin nanoparticles (IDA-NPs) were formulated as previously described by Ma et al. (20), and BODIPY FL $\mathrm{C}_{12}-\mathrm{NPs}_{\mathrm{s}}$ were formulated by identical methods. IDA$\mathrm{NPs}_{\mathrm{s}}$ were composed of idarubicin hydrochloride $(0.2 \mathrm{mg}$ idarubicin/ml $)$, sodium tetradecyl sulfate $(0.159 \mathrm{mg} / \mathrm{ml})$, emulsifying wax (2 mg/ml), Polyoxyl 20-stearyl ether [Brij 78] (2.3 mg/ml), and D-alpha-tocopheryl polyethylene glycol 1,000 succinate [vitamin-E TPGS] (3 mg/ml). Idarubicin nanoparticles had an average size of $95 \mathrm{~nm} \pm$ 0.2 , polydispersity index of 0.157 and zeta potential of $-13.7 \mathrm{mV} \pm 2.1$, and were stable over at least seven days at $4^{\circ} \mathrm{C}$. Idarubicin was chosen as a model probe for these studies since the formulation had already been developed and idarubicin is highly fluorescent.

The BODIPY nanoparticles (BODIPY-NPs) were composed of BODIPY FL $\mathrm{C}_{12}(50 \mu \mathrm{g} / \mathrm{ml})$, emulsifying wax (2 mg/ml), and Polyoxyl 20-stearyl ether [Brij 78] $(4.0 \mathrm{mg} / \mathrm{ml})$. BODIPY-NPs had an average size of $86 \mathrm{~nm}$, polydispersity index of 0.043 , zeta potential of $-13.8 \mathrm{mV} \pm 0.16$, and were stable over at least seven days at $4^{\circ} \mathrm{C}$. Please refer to Table I for a complete description of nanoparticle characteristics and experimental applications.

\section{Qualitative Assessment of Solid Lipid Nanoparticle and FluoSphere Internalization in OSCC Cell Monolayer}

OSCG cells were seeded in 8-well LabTek chamber slides at $1 \times 10^{5}$ cells/well. The cells were incubated with nanoparticles at varying concentrations and time points, as shown in Table $\mathrm{I}$, at $37^{\circ} \mathrm{C}, 5 \% \mathrm{CO}_{2}$ in $\mathrm{DMEM} / \mathrm{F} 12$ 
Table I Nanoparticle Characteristics and Experimental Application

\begin{tabular}{|c|c|c|c|c|}
\hline Nanoparticle & Size ( $\zeta$-potential) & Fluorescence (ex/em) & Nanoparticle composition & Experimental application \\
\hline $\begin{array}{l}\text { Solid lipid NPs } \\
\text { Idarubicin-NP } \\
\text { (IDA-NPs) }\end{array}$ & $95 \mathrm{~nm}(-13.7 \mathrm{mV} \pm 2.1)$ & $485 \mathrm{~nm} / 542 \mathrm{~nm}$ & $\begin{array}{l}\text { Idarubicin HCl, Sodium Tetradecyl } \\
\text { Sulfate (STS), emulsifying wax, } \\
\text { Brij® 78, D-alpha-tocopheryl } \\
\text { polyethylene glycol I,000 succinate } \\
\text { (Vitamin E TPGS) }\end{array}$ & $\begin{array}{l}\text { Initial qualitative (Fig. 3A and B) and } \\
\text { quantitative (nanoparticle versus bolus } \\
\text { delivery) (Fig. 4) studies in SCC4, } \\
\text { SCC9, and SCCI } 5 \text { cell lines. Following } \\
30 \text { min, 2,500 nM IDA-NP incubation } \\
\text { for qualitative analysis, nuclei were } \\
\text { stained with } 300 \text { nM DAPI. }\end{array}$ \\
\hline $\begin{array}{l}\text { Solid lipid NPs } \\
\text { BODIPY } ® \text { FL } C_{12} \\
\text { NP (BODIPY-NPs) }\end{array}$ & $86 \mathrm{~nm}(-13.8 \mathrm{mV} \pm 0.16)$ & $500 \mathrm{~nm} / 510 \mathrm{~nm}$ & $\begin{array}{l}\text { BODIPY® FL } C_{12} \text {, Sodium } \\
\text { Tetradecyl Sulfate (STS), } \\
\text { Emulsifying wax, Brij }{ }^{\circledR} 78\end{array}$ & $\begin{array}{l}\text { Qualitative internalization study in } \\
\text { SCC4 and SCCI } 5 \text { cell lines. Following } \\
6 \mathrm{~h}, \mathrm{I} \mu \mathrm{g} \text { BODIPY-NP incubation, } \\
\text { exogenous fluorescence was } \\
\text { quenched with } 0.08 \% \text { Trypan blue } \\
\text { (49) and nuclei stained with } 300 \mathrm{nM} \\
\text { DAPI (Fig. } 3 \mathrm{C} \text { and D). }\end{array}$ \\
\hline $\begin{array}{l}\text { FluoSphere }{ }^{N} \text { NPs } \\
\text { yellow-green }\end{array}$ & $\begin{array}{l}210 \mathrm{~nm}(-9.9 \mathrm{mV} \pm \\
1.65)(33)\end{array}$ & $505 \mathrm{~nm} / 5 \mathrm{I} 5 \mathrm{~nm}$ & $\begin{array}{l}\text { Biotin-labeled, fluorescein-loaded, } \\
\text { polystyrene nanoparticles }\end{array}$ & 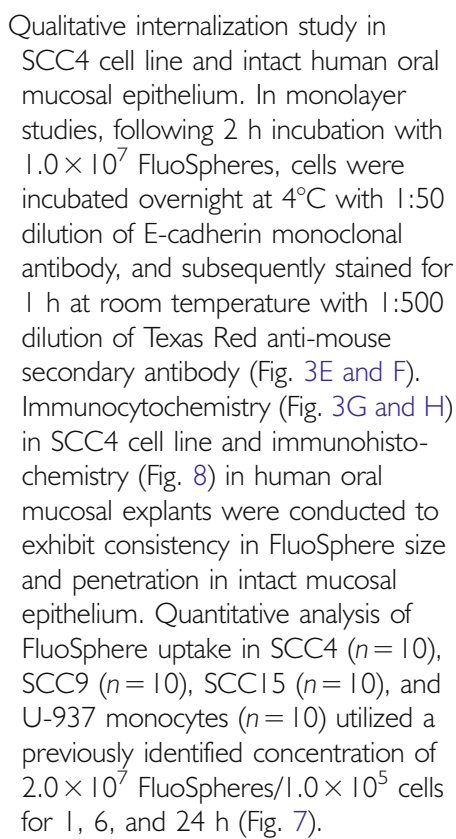 \\
\hline
\end{tabular}

medium supplemented with $10 \%$ heat-inactivated fetal bovine serum. Following incubation and nuclear staining, cell samples were mounted in Vectashield mounting medium and visualized using wide-field fluorescence microscopy (Olympus BX51); images were captured with a Nikon DSFil high-resolution digital camera.

\section{Quantitative Assessment of Solid Lipid Nanoparticle and FluoSphere Internalization in OSCC Cell Monolayer}

OSCG cells were seeded in 96 -well plates at $1 \times 10^{5}$ cells/well, and treated in triplicate with nanoparticles at varying concentrations and time points (Table I). Cells were washed with phosphate-buffered saline, extracellular fluorescence quenched with a $0.08 \%$ Trypan blue solution, and internal fluorescence was quantified using an LS50B luminescence spectrometer
(Perkin Elmer; Waltham, MA, USA), and more recent quantitative studies (FluoSpheres) with a FLUOstar Omega microplate reader (BMG Labtech, Durham, NC).

\section{Evaluation of FluoSphere Nanoparticle Penetration and Uptake in Oral Mucosal Tissue Explants}

To determine whether or not topically applied nanoparticles could penetrate the outer epithelial layers and reach the chemopreventive targets, i.e., proliferating basal and peribasilar epithelial cells, oral mucosal tissues were obtained from ten persons undergoing elective oral surgical procedures. Mucoadhesive bi-layer thin-film composites (TFG) were formulated as described in our previous reports $(21,22)$. The TFCs were cut with a circular arch punch to a diameter of $7 \mathrm{~cm}$ and subsequently trimmed with a scalpel to the corresponding oral explant size. Tissue explant 
surface epithelium was initially identified to direct explant orientation and TFC placement. Explants were then placed on a FIBRACOL-Plus sponge in DMEM/F12 supplemented with $10 \%$ heat-inactivated FBS and $40 \mu \mathrm{g} / \mathrm{ml}$ gentamicin. Fifty-million tissue-fixation-stable FluoSpheres were post-loaded onto the TFC by aliquoting $15 \mu \mathrm{l}$ of suspension onto the mucoadhesive layer of the TFCs and air-dried at room temperature for $45 \mathrm{~min}$. The FluoSphere post-loaded TFGs were then placed directly on the epithelial surface of the oral explant, as shown in Fig. 1. The explants were incubated with the post-loaded TFCs at $37^{\circ} \mathrm{C}, 5 \% \mathrm{CO}_{2}$ for $3 \mathrm{~h}$. Following incubation, the TFCs were removed, and the explants were washed five times in $1 \times$ PBS, subsequently fixed with $10 \%$ formalin, followed by standard tissue processing. Control tissues received identical TFC treatment with the exception of FluoSphere addition.

The potential for artifact-induced FluoSphere crosscontamination was alleviated by initially sectioning the nanoparticle-free control tissues and thoroughly cleaning the microtome blade after sectioning each successive Fluosphere tissue explant specimen. To avoid the prospect for FluoSphere incorporation from the sides of the explant, histologic sections were obtained from the deeper portions of the specimens. Tissue sections were then deparaffinized, rehydrated, and counterstained with hematoxylin and eosin. For each sample, nanoparticle penetration into the respective epithelial compartments (i.e., surface third, middle third, basal third) and underlying connective tissue was determined, as shown in Fig. 2.

\section{Determination of Phase-III Efflux Transporter Expression in Normal Human Oral Mucosal Tissue and Cultured Human OSCC Cells by Western Blot Analysis}

OSGC cells (SCG4, SCG9, SCG15, SCG25), 15 normal human oral mucosal samples, MCF-7 cells (BCRP/MRP1

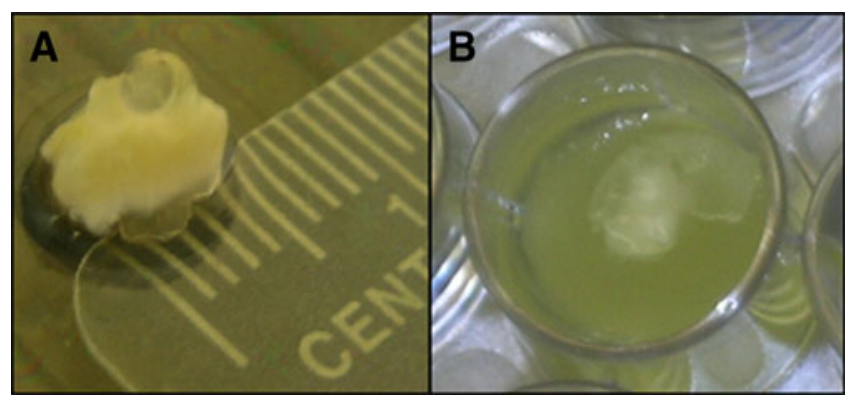

Fig. I Orientation of normal human oral mucosal tissue explants and FluoSphere incubation setup. A Mucosal explant surface epithelium was initially identified prior to incubation setup. Explants measured, on average, $5 \mathrm{~mm}$ in diameter. B Mucosal explants were oriented epithelial side up in a fibrocollagen sponge partially immersed in culture medium. FluoSphere $\left(5.0 \times 10^{7}\right)$ post-loaded mucoadhesive thin-film composites were then placed directly on the epithelial surface and incubated at $37^{\circ} \mathrm{C}$ for $3 \mathrm{~h}$.

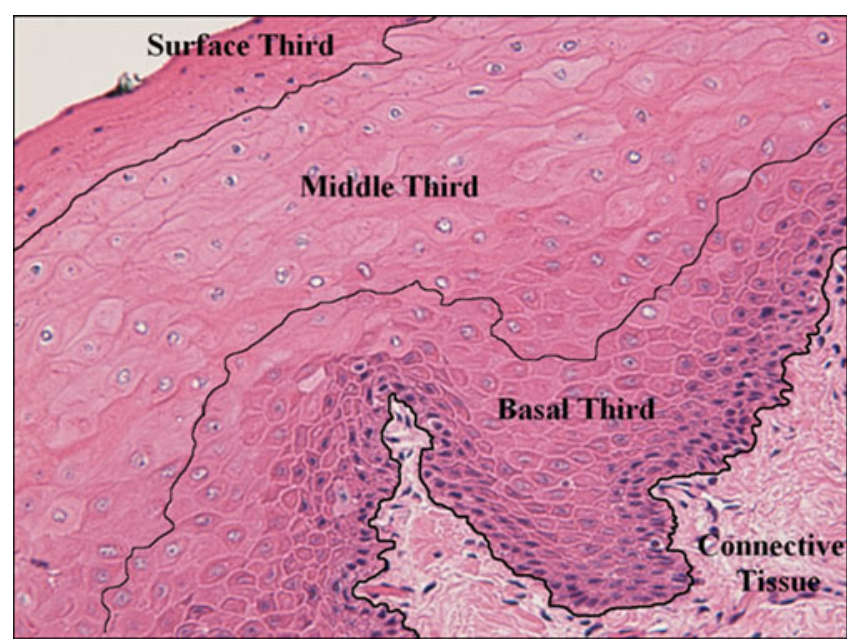

Fig. 2 The quantification scheme used to assess FluoSphere penetration divided the oral stratified squamous epithelium of mucosal explants into a surface third, middle third, and basal third. Nanoparticle penetration through the basement membrane was recorded in the connective tissue category.

positive control), HCT-15 cells (P-gp positive control), or rat liver extract (MRP1 positive control) were cultured/ collected as described and protein extracted with M-PER®. Protein samples were quantified using the Bradford protein assay (23) and $30 \mu \mathrm{g}$ loaded onto a 10\% SDS-polyacrylamide gel and subjected to electrophoresis. Following electrotransfer onto PVDF membranes, the blots were blocked for $1 \mathrm{~h}$ at room temperature with $1 \times$ Tris-buffered saline containing $0.2 \%$ Tween- 20 and $5 \%$ non-fat dry milk, and subsequently incubated overnight with the respective primary antibody dilution (BCRP 1:250, MRP1 1:200, P-gp 1:100, $\beta$-actin 1:20,000). Immune complexes were detected by incubation for $1 \mathrm{~h}$ at room temperature with horseradish peroxidaselinked secondary antibody (goat anti-mouse IgG-HRP 1:1,000, donkey anti-goat IgG-HRP 1:2,000). Immunoreactive bands were detected by 5 min incubation with ECL-plus detection system and subsequent exposure on CL-Xposure films.

\section{Confirmation of MRPI and BCRP Expression in Normal Human Oral Mucosa and OSCC Specimens via Immunohistochemistry}

Paraffin-imbedded tissues were deparaffinized and rehydrated, and endogenous peroxidase activity was blocked by pretreatment with $3 \% \mathrm{H}_{2} \mathrm{O}_{2}$, followed by microwave processing to facilitate antigen retrieval. Sections were subsequently treated with $5 \%$ normal serum, $1 \%$ bovine serum albumin, and $0.05 \%$ Tween-20 for $1 \mathrm{~h}$, and then incubated with either the primary antibody (MRP1: 1:50, BCRP 1:20, Pgp: 1:100) or PBS (negative control) at $4^{\circ} \mathrm{C}$ overnight. Next, samples were incubated with the respective biotinylated secondary antibody for $1 \mathrm{~h}$ at room temperature. Vectastain $\mathrm{ABC}$ reagent 
was then applied and sections incubated for $30 \mathrm{~min}$. Immunoreactions were visualized using the DAB substrate, followed by hematoxylin counterstaining. Images were captured using a Nikon DS-Fil high-resolution digital camera and analyzed using Image-Pro Plus 6.2 software (Media Cybernetics, Bethesda, MD, USA).

\section{Statistical Analysis}

IDA-NP versus free-IDA internalization was compared using the Mann Whitney U two-tailed test. Individual cell line FluoSphere internalization was analyzed using the Wilcoxon one-tailed signed rank test. Comparison of inter-cell line FluoSphere uptake was compared using the Kruskal-Wallis Nonparametric Analysis of Variance, followed by a Dunn's Multiple Comparisons post-test.

\section{RESULTS}

\section{IDA-Nanoparticles Internalized and Retained at High Levels in Cultured OSCC Cells}

The initial treatment of OSCG cells with IDA-NPs in LabTek chamber slides suggested that the SLNs were internalized by the cells in monolayer (Fig. 3A and B). Furthermore, the quantitative comparison of IDA-NP versus free-IDA internalization exhibited an accelerated uptake of free-IDA compared to IDA-NP at $1 \mathrm{~h}$ [1,000 nM: average
free-IDA internalization (21.08 \pm 5.33$)$; IDA-NP internalization $(12.87 \pm 4.32) \quad p<0.002, n=18]$, but the overall maximum retention was obtained with nanoparticle delivery at $6 \mathrm{~h}$ [IDA-NP internalization: 2,500 nM: 43.53 \pm 8.42 , 5,000 nM: $64.44 \pm 12.71$; Free-IDA internalization: 2,500 nM: 27.61 $\pm 5.66, p<0.01, n=18 ; 5,000 \mathrm{nM:} 31.06 \pm$ $7.24, p<0.001, n=18]$. Interestingly, free-IDA internalization exhibited a plateau effect after $6 \mathrm{~h}$, while the IDA-NP portrayed a dose- and time-dependent uptake with maximal levels obtained at the highest dose and longest incubation time (Fig. 4). These data, which showed higher final intracellular levels with SLN delivery, suggested the potential for SLNs to overcome phase-III transporter-mediated efflux (P-gp, BCRP, and/or MRPl), while free-IDA appeared susceptible to the efflux mechanism.

\section{Expression of Phase-III Transporters (MRP I and BCRP) in Normal Oral Mucosal Tissue, OSCC Tissue, and Cultured OSCC Cells (MRPI)}

Subsequent Western blot and immunohistochemistry analyses to evaluate for the presence of phase-III transporters showed a cell- and tissue-dependent specificity. Western blot analysis confirmed the presence of BCRP in all (15/15) normal human oral mucosal tissues (Fig. 5A), which also exhibited higher levels relative to the unchallenged MCF-7 positive control. In contrast, the OSCG cells did not show a BCRP-corresponding band (data not shown). Furthermore, BCRP immunohistochemistry exhibited strong staining in
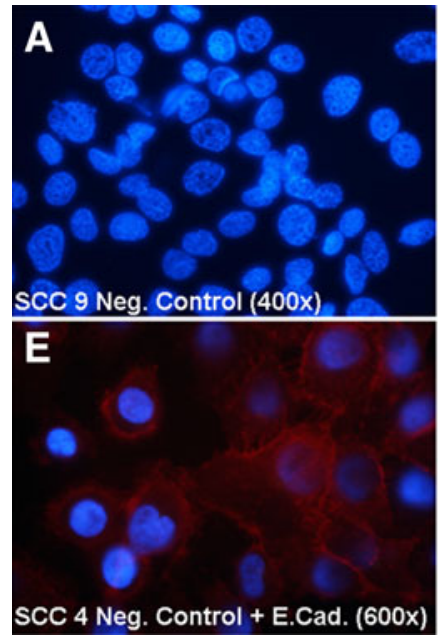
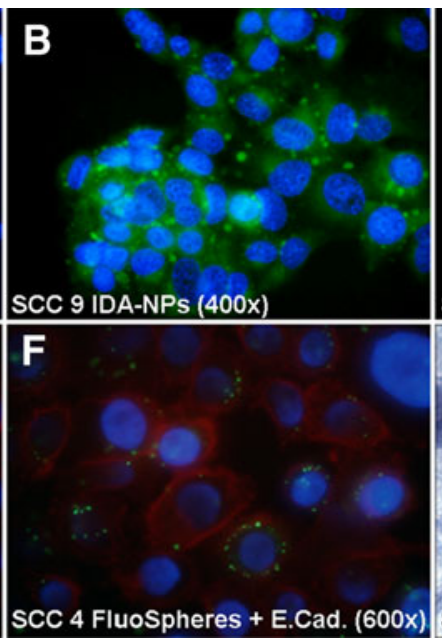
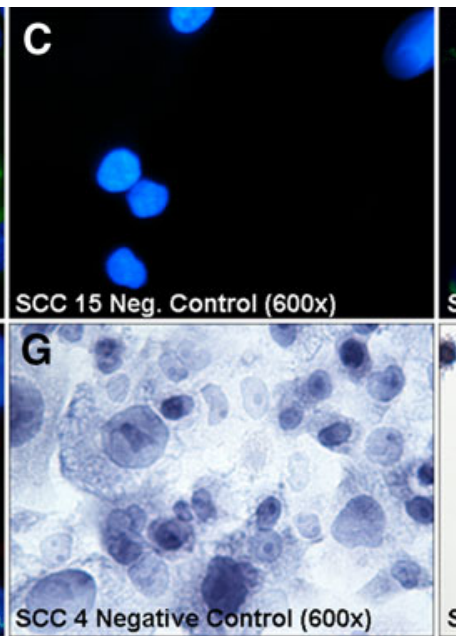

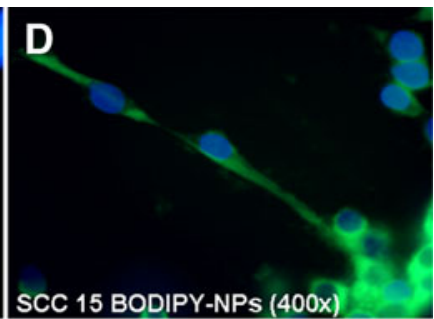

H

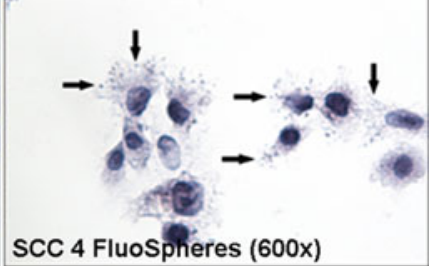

Fig. 3 Representative photomicrographs of SLN and FluoSphere internalization studies in monolayer-cultured human OSCC cells. A IDA-NP internalization negative control, cells were not treated with SLNs. Nuclei (blue) were stained with 300 nM DAPI. B SCC4, SCC9, and SCCI5 cells internalized IDA-NPs (green) following 30 min incubation with 2500 nM IDA-NPs (only SCC9 shown). C BODIPY-NP internalization negative control. D SCC 4 and SCCI 5 cells internalized BODIPY-NPs (green) following $6 \mathrm{~h}$ incubation with I $\mu \mathrm{g}$ BODIPY-NPs and subsequent quenching of extracellular fluorescence with $0.08 \%$ Trypan blue (only SCCI5 shown). E FluoSphere internalization negative control with E-cadherin (to delineate cell boundaries) immunofluorescent staining. F SCC4 cells internalized FluoSpheres (green) following 2 h incubation with $1.0 \times 10^{7}$ FluoSpheres. G FluoSphere immunocytochemistry negative control. H Immunocytochemistry evaluation of SCC4 cell internalization of FluoSpheres (arrows) to confirm size consistency utilizing both fluorescence and immunocytochemical analyses. 


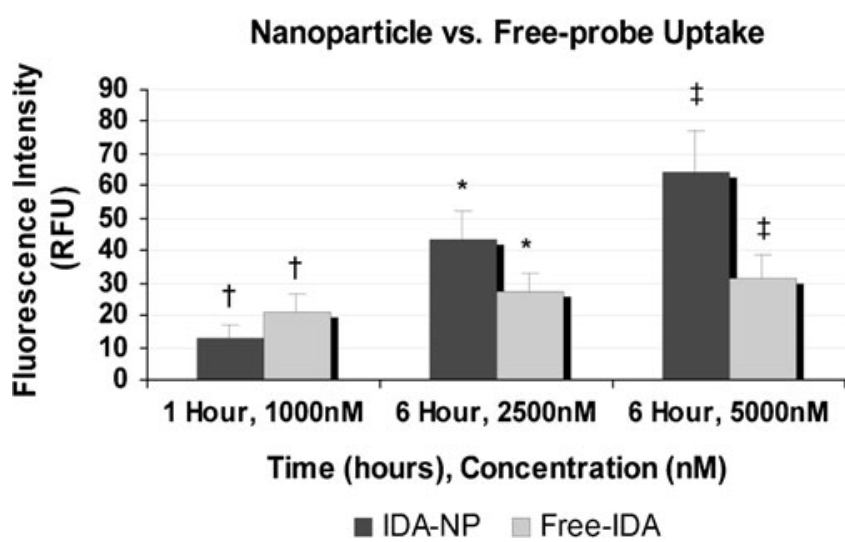

Fig. 4 Idarubicin-nanoparticle delivery provided higher, sustained levels of intracellular idarubicin relative to free-idarubicin delivery in human OSCC cells. The internalization of free-IDA was more rapid than IDA-NP after I $h$ at $1000 \mathrm{nM}$ (free-IDA: $21.08 \pm 5.33$ vs. IDA-NP: 12.87 \pm 4.32 ). However, the maximum uptake of IDA-NP was greater than free-IDA after $6 \mathrm{~h}$ at $2500 \mathrm{nM}$ (IDA-NP: $43.53 \pm 8.42$ vs. free-IDA: $27.6 \mathrm{I} \pm 5.66$ ) and $5000 \mathrm{nM}$ (IDA-NP: $64.44 \pm 12.7 \mid$ vs. free-IDA: $31.06 \pm 7.24)$. [Data collected from three oral SCC cell lines, mean \pm SD, $n=18, * P \leq 0.01$ ${ }^{\dagger} P \leq 0.002,{ }^{\ddagger} P \leq 0.00$ I; IDA-NP samples compared to free-IDA samples; Mann-Whitney $U$ two-tailed Test].

the basal and spinous layers of the normal oral epithelium in $9 / 10$ specimens (Fig. 6A) and showed selective staining at the periphery of the tumor nests in 5/5 OSCG specimens (Fig. 6B).

The MRP1 Western blot analysis, on the other hand, exhibited expression in all $(15 / 15)$ normal oral mucosal tissues (Fig. 5B) and to varied intensities in 4/4 OSCC cell lines (Fig. 5C). While the intact molecular weight of MRP1 is $190 \mathrm{kDa}$, our findings were consistent with the literature which reports that MRP1 is sensitive to cleavage into two fragments of approximately $\sim 75 \mathrm{kDa}$ and $\sim 120 \mathrm{kDa}$ (24). Furthermore, MRP1 immunohistochemistry also revealed positive staining in the basal and spinous layers of epithelium in 8/8 normal oral mucosal tissues (Fig. 6C) and staining throughout the tumor nests in 3/5 OSCG specimens (Fig. 6D). Additional Western blot and immunohistochemical analyses confirmed the absence of P-glycoprotein in 7/7 normal human oral mucosal tissues (Fig. 6E), 3/3 OSCC tissues (Fig. 6F), and 4/4 OSCG cells (Western blot not shown) relative to the positive control HCT-15 cell line and human minor salivary gland tissue.

\section{Qualitative Confirmation of Solid Lipid Nanoparticle Internalization by Monolayer OSCC Cells}

The capacity for OSCG cells in monolayer culture to internalize model SLNs was analyzed using wide-field fluorescent microscopy. Our data, which demonstrated the presence of intracellular fluorescent nanoparticles following quenching of non-internalized, extracellular particles with Trypan blue, confirmed the definitive internalization of the BODIPY-NPs in both of the OSCC cell lines evaluated (Fig. 3C and D).

\section{Fixation-Stable FluoSpheres Readily Internalized by Monolayer Oral SCC Cells}

FluoSphere uptake in monolayer OSCG cells was qualitatively assessed by both fluorescence microscopy (Fig. 3E and F) and immunocytochemistry (Fig. 3G and H). Similar to the smaller diameter SLN studies, i.e., $95 \mathrm{~nm}$ IDA-NP

A

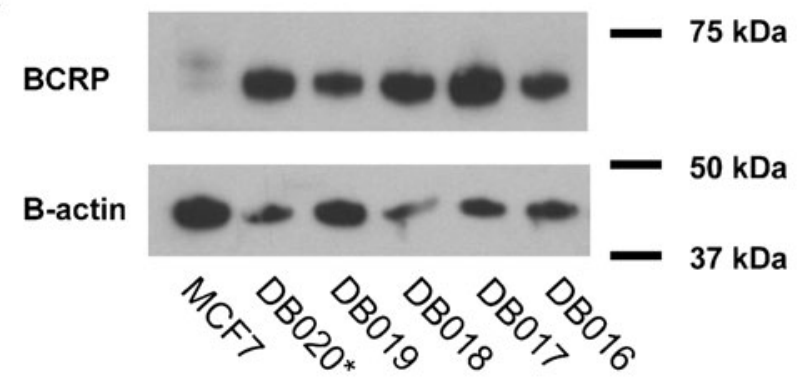

B

MRP1

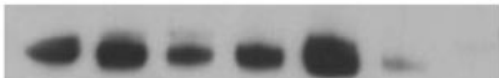

75 kDa

Bactin

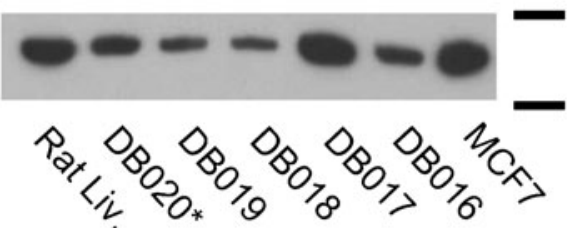

$50 \mathrm{kDa}$

37 kDa

C

$150 \mathrm{kDa}$

MRP1 Fragment 1

$100 \mathrm{kDa}$

MRP1 Fragment 2

$75 \mathrm{kDa}$

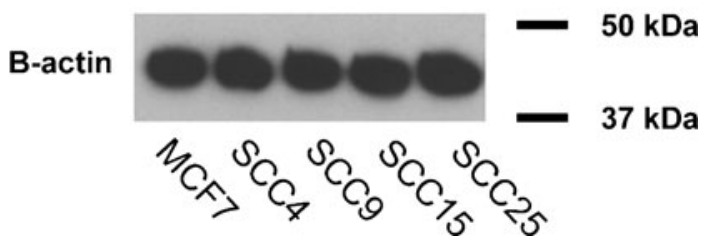

Fig. 5 Evaluation of phase-III efflux transporter expression in normal human oral mucosa and human OSCC cells via Western blot analysis. A The presence of BCRP in 15 normal oral mucosal samples (DBOI6DB020 are five representative samples) was confirmed relative to MCF-7 positive control. B MRPI expression was confirmed in 15 normal oral mucosal samples (DBO I 6-DB020 are five representative samples) relative to rat liver extract and MCF-7 positive controls. C MRPI expression was also confirmed in SCC4 and SCC9 cells, and to a lesser extent in SCCI5 and SCC25 cells. While the expected MRPI molecular weight is $190 \mathrm{kDa}$, these data are consistent with the literature describing cleavage fragments of $\sim 75 \mathrm{kDa}$ and $\sim 120 \mathrm{kDa}(24)$. 
Fig. 6 Evaluation of phase-III efflux transporter expression in normal human oral mucosa and human OSCC tissue via immunohistochemistry. The presence of $\operatorname{BCRP}(\mathbf{A})$ and $\mathrm{MRPI}(\mathbf{C})$ is evident in the basal and spinous layers of the normal oral epithelium, which are key sites for the protection of cells actively replicating DNA. Note, this tissue is from the same specimen, i.e., DB020, used in the Western blots, indicating the focused expression of these efflux pumps in the epithelium rather than connective tissue. The OSCC tissue samples also express BCRP (B) and MRPI (D), which are both focused in the malignant epithelial cell tumor nests. Notably, P-gp expression is absent in normal oral mucosal tissue (E) and OSCC tissue (F), which was also confirmed by Western blot analyses (data not shown)

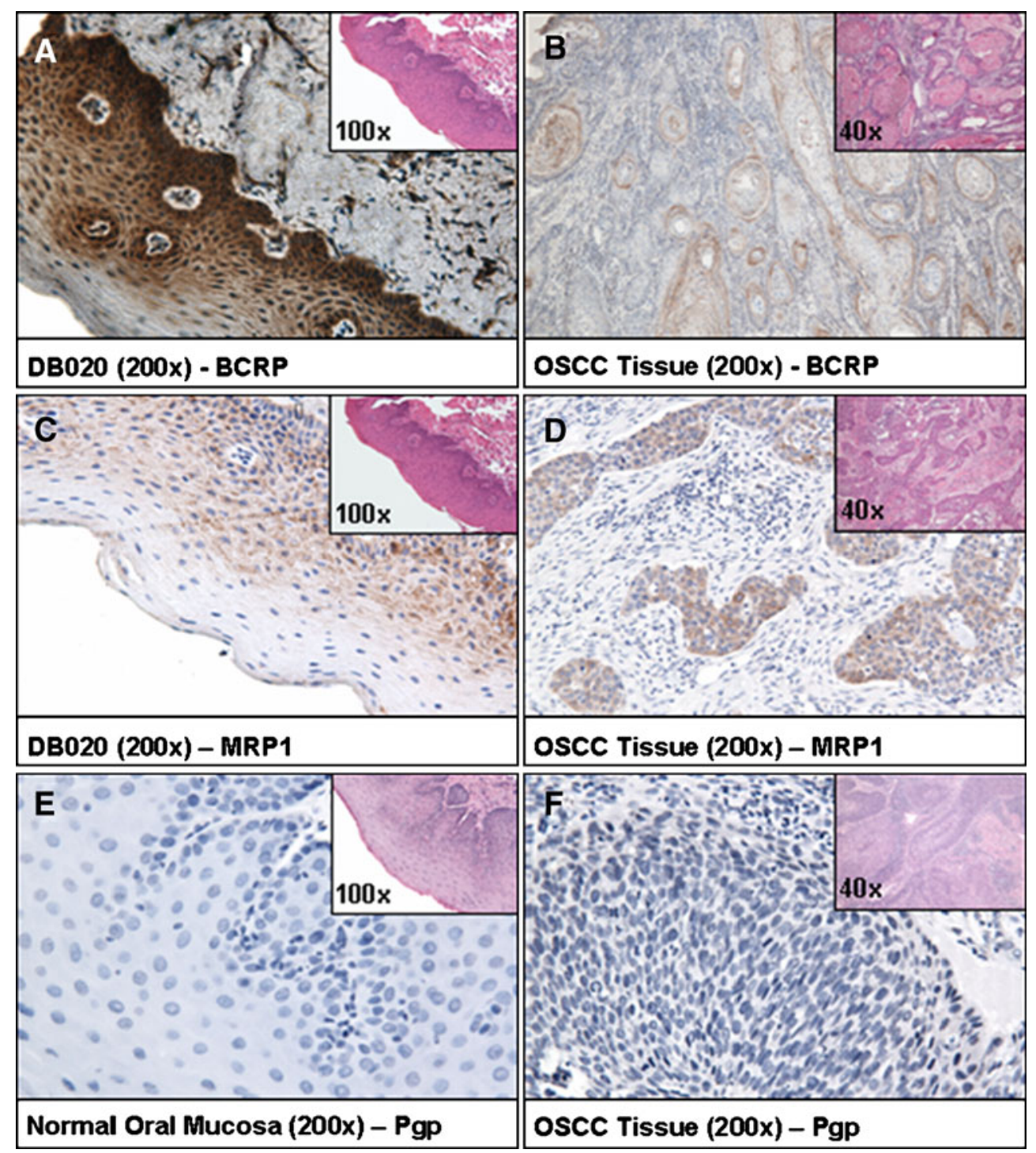

and $86 \mathrm{~nm}$ BODIPY-NP, the larger diameter FluoSpheres, $200 \mathrm{~nm}$, were also internalized by OSCC cells in monolayer (3/3 cell lines).

Corresponding quantitative analyses of FluoSphere uptake were both cell-origin- and cell-line-dependent. As would be anticipated based on their phagocytic origin, U-937 cells exhibited the highest FluoSphere internalization at all time points, and all OSCG cell lines internalized FluoSpheres, albeit to a lesser extent. While all OSCG cell lines demonstrated quantifiable nanoparticle uptake at 6 and $24 \mathrm{~h}$ (Fig. 7A and $\mathrm{C}$ ), the greatest internalization was apparent in the SCC4 cell line (6 h: 9.84\%, 24 h: 18.38\% relative to the uptake of U-937 monocytes, Fig. $7 \mathrm{~B}$ and D). Not unexpectedly, at the $6 \mathrm{~h}$ time point, monocytes had internalized the largest amount of FluoSpheres, resulting in significantly greater internalization relative to SCC4 $(p<0.05)$, SCC9 $(p<0.001)$, and SCC15 cells $(p<0.001)$. Although monocyte intracellular levels of FluoSpheres decreased from the 6 to $24 \mathrm{~h}$ time points, monocyte levels were still significantly higher at $24 \mathrm{~h}$ relative to all oral $\mathrm{SCC}$ cells (SCG4: $p<0.01$, SCC9: $p<0.001$, SCC15: $p<0.001$ ).

Appreciable cell-line-dependent heterogeneity was observed among the OSCG cell lines. Although the $1 \mathrm{~h}$ time point did not provide ample time for internalization in the SCC9 and SCC15 cell lines, the SCC4 cells exhibited considerable uptake (data not shown). This trend also translated to a significantly higher rate of FluoSphere internalization in SCC4 cells relative to SCC9 and SCG15 cells at the $6 \mathrm{~h}$ time point $(p<0.01)$. At the $24 \mathrm{~h}$ time point, however, total intracellular levels of FluoSpheres in SCC4 cells were reduced relative to their $6 \mathrm{~h}$ time point. In contrast, comparison of the $6 \mathrm{~h}$ relative to $24 \mathrm{~h}$ time points in SCC9 and SCC15, cells showed increased intracellular FluoSphere levels. Furthermore, all 6 and $24 \mathrm{~h}$ samples individually demonstrated significant uptake, as shown in Fig. 7A and C (6 h: SCC4: $p<0.001$, SCC9: $p<0.025$, 

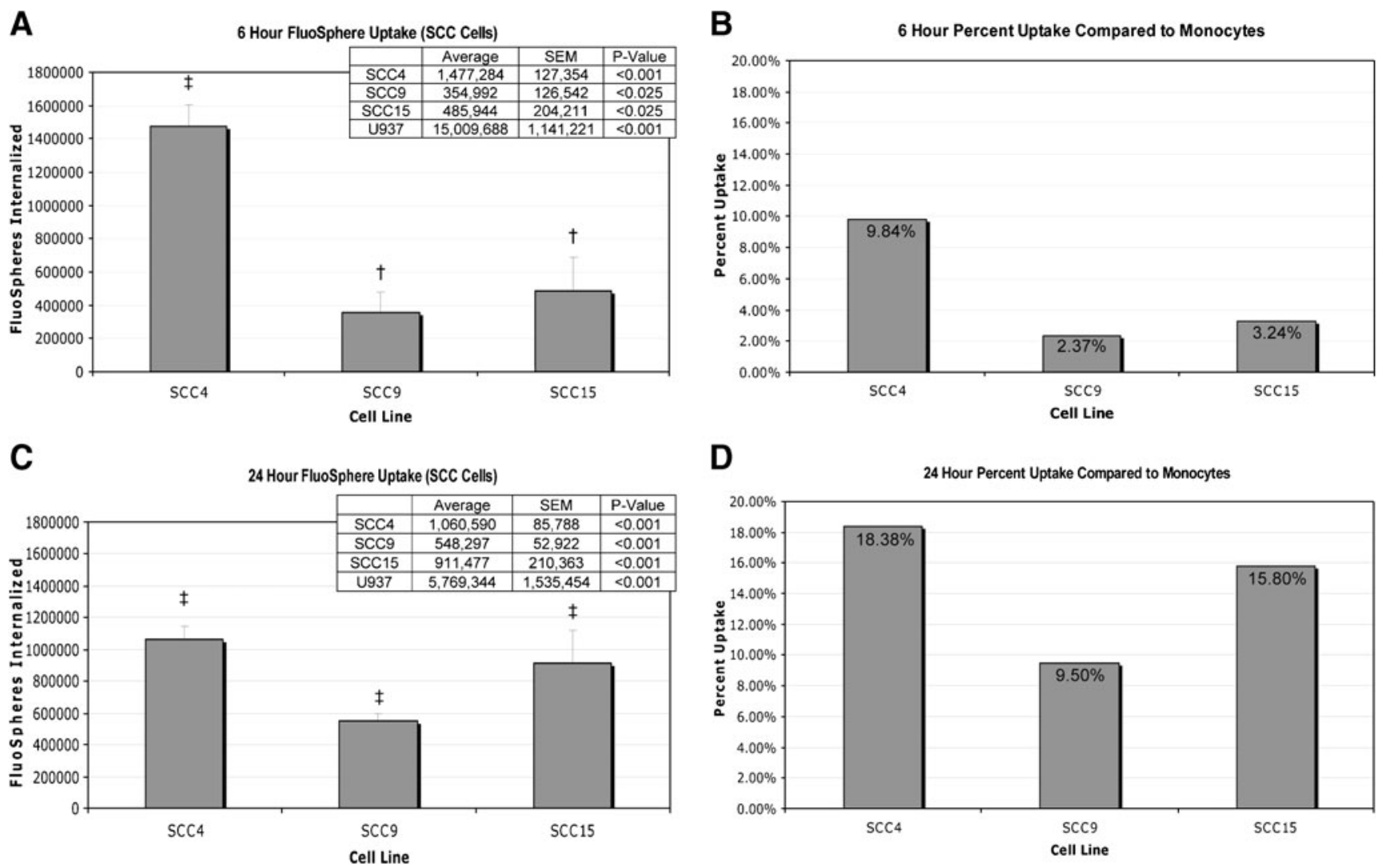

Fig. 7 Comparison of FluoSphere internalization by human OSCC cells and human monocytes. FluoSphere internalization was cell-line-dependent, with SCC4 cells exhibiting significantly greater internalization after I h (data not shown) and $6 \mathrm{~h}$ (A) incubations compared to SCC9 and SCCI5 cells. As expected, human monocytes' FluoSphere uptake was significantly greater than all OSCC cell lines at $6 \mathrm{~h}$ (B). After $24 \mathrm{~h}$ of FluoSphere incubation, however, SCC4 cells exhibit a decrease of intracellular FluoSphere amount (possibly due to MRPI-mediated efflux), while the SCC9 and SCCI 5 cells exhibit steady internalization over the full $24 \mathrm{~h}$ time course $(\mathbf{C})$. Furthermore, at $24 \mathrm{~h}$, OSCC cells demonstrate increased internalization relative to human monocytes, but the overall decrease in monocyte internalization at $24 \mathrm{~h}$ is possibly attributed to decreased cell viability. [mean $\pm \mathrm{SEM}, n=10,{ }^{\dagger} P \leq 0.025$,

${ }^{\ddagger} P \leq 0.00$ I; Wilcoxon Signed Rank, one-tailed test, $\left.\mathrm{H}_{0}: \mu=0\right]$.

SCC15: $p<0.025$, U-937: $p<0.001 ; 24$ h: SCC4: $p<0.001$, SCC9: $p<0.001$, SCC15: $p<0.001, \mathrm{U}-937: p<0.001)$.

\section{FluoSphere Nanoparticles Penetrate Intact Human Oral Stratified Squamous Epithelium and are Retained in Basal Cells and Underlying Connective Tissue}

Application of fixation-stable FluoSpheres to mucosal explants $(n=10)$ demonstrated the capacity for nanoparticle penetration and subsequent internalization by intact human oral epithelium. In addition, nanoparticle retention was not restricted to the superficial layer of the surface epithelium. Intact nanoparticles were visualized in the superficial third of the epithelium in 10/10 explants, the middle epithelial third in $7 / 10$ explants, and the basilar third in $7 / 10$ explants. Notably, intact nanoparticles were also observed in the superficial underlying connective tissue in $7 / 10$ explants (Fig. 8 and Table II), implying penetration of intact basement membranes. Due to the need for surgery at multiple sites, one tissue donor (patient 5) donated specimens from multiple tissue sites, of which all four demonstrated full-thickness penetration of the entire epithelium by FluoSpheres.

\section{DISCUSSION}

Most oral topical agents rely on aqueous-based gels as delivery vehicles, e.g., Lidex ${ }^{\circledR}$, Temovate ${ }^{\circledR}$, and the FBR gel used in our phase I/II clinical trials $(10,11,25)$. While gels represent the most common oral delivery strategy, oral rinses (6), local injections (26), and mucoadhesive patches $(21,22)$ are also frequently used. Due to the lack of compatibility, it is challenging to formulate poorly water soluble and/or unstable compounds, such as fenretinide, in topical aqueous-based delivery vehicles (27). This shortcoming in topical oral drug delivery was the basis for these current studies, which assessed the feasibility of nanoparticle-based formulations for local delivery of such drugs to the oral mucosa. 
Fig. 8 FluoSphere penetration in representative samples of intact normal oral stratified squamous epithelium. Following an elective oral surgical procedure, normal oral mucosa was collected and bisected ( $n=10$ samples). One half of the full-thickness mucosal tissue was used as an explantmatched negative control $(\mathbf{A})$, which was incubated in the absence of FluoSpheres. The other half of the matched mucosal tissue was used for the analysis of FluoSphere penetration and internalization (B), as described in Fig. 2 and presented in Table II. As demonstrated by the arrows (B), the nanoparticles penetrate the full thickness of oral epithelial layers and basement membrane.

Furthermore, immunohistochemistry analysis of FluoSphere-treated explants show full epithelial penetration and intracellular retention of nanoparticles in MRPI (C) and BCRP (D) expressing tissue.
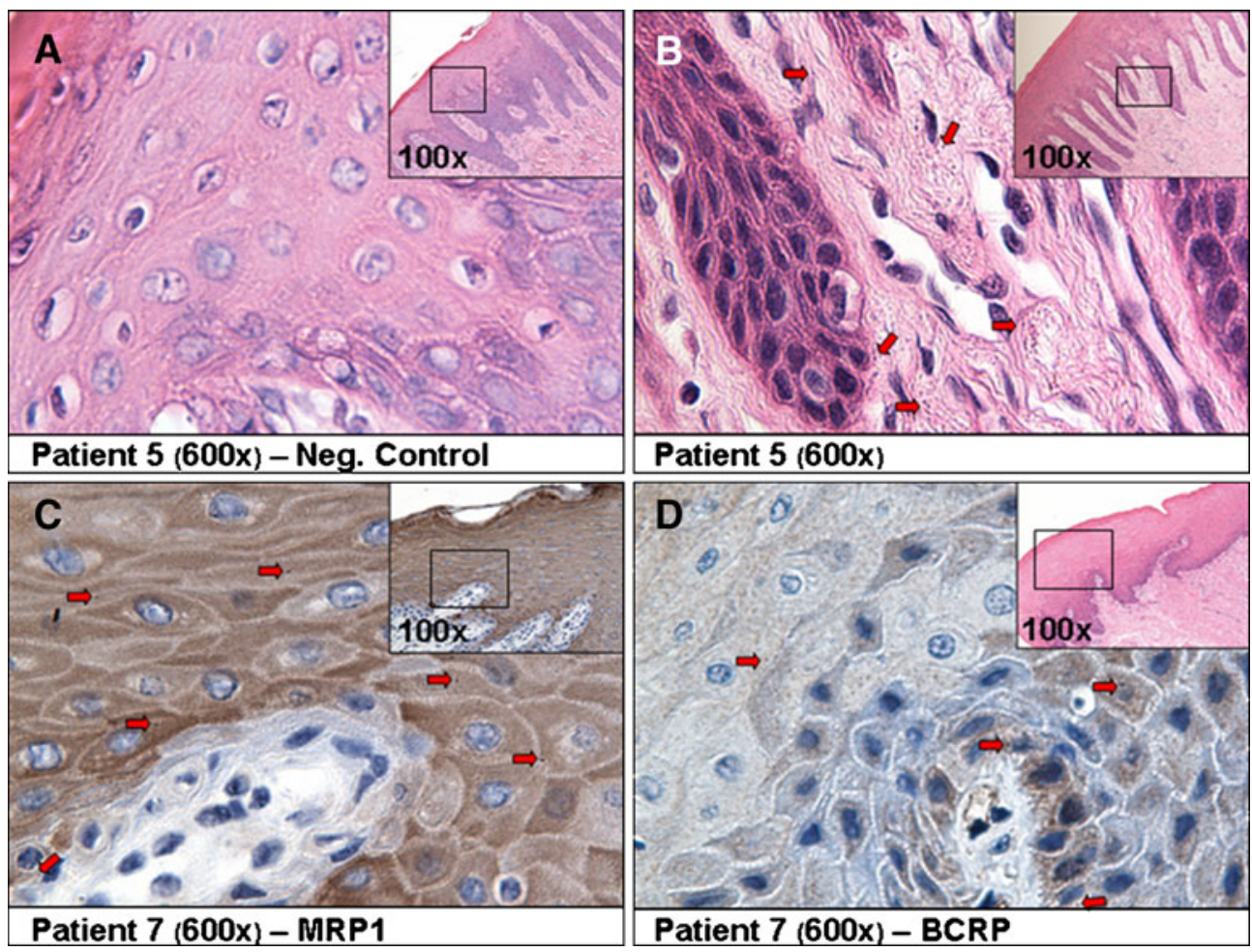

Our nanoparticle internalization results compare favorably to previous studies, which demonstrated that cultured human oral epithelial cells and dissociated oral and esophageal epithelial cells internalized variably sized $(10 \mathrm{~nm}-100 \mathrm{~nm})$ fluorescently labeled polystyrene nanoparticles in a dose-dependent fashion (28-31). Based on their lack of biodegradability and the covalent linkage of fluorescein to polystyrene, FluoSpheres (i.e., polystyrene nanoparticles) represent a convenient tool to evaluate in vitro and ex vivo endocytosis (32). The inability, however, to metabolize polystyrene and the potential for polystyrene nanoparticle interference with cell metabolism, e.g., inhibition of cytochrome $\mathrm{P} 450$ complexes, precludes the use of such nanoparticle formulations for local oral delivery (33). It is therefore necessary to identify a nanoparticle delivery system that has appropriate biocompatibility. The model SLNs formulated by our labs (i.e., IDA-NPs and BODIPY-NPs) have been shown to have excellent hemo-

Table II FluoSphere ${ }^{\circledR}$ Penetration in Normal Human Oral Mucosal Tissue Explants

\begin{tabular}{llllllll}
\hline Patient & Surface & Middle & Basal & Connective & Age/Sex & Race & Alcohol/Tobacco history \\
\hline 1 & $\checkmark$ & $\checkmark$ & $\checkmark$ & $\checkmark$ & $27 \mathrm{~F}$ & Asian/Pacific Islander & None \\
2 & $\checkmark$ & $\checkmark$ & $\checkmark$ & $\checkmark$ & $26 \mathrm{~F}$ & White/Non-Hispanic & None \\
3 & $\checkmark$ & - & - & - & $69 \mathrm{~F}$ & White/Non-Hispanic & None \\
4 & $\checkmark$ & - & - & - & $5 \mathrm{M}$ & White/Non-Hispanic & Prior alcohol and tobacco use \\
$5^{a}$ & $\checkmark$ & $\checkmark$ & $\checkmark$ & $\checkmark$ & $50 \mathrm{M}$ & White/Non-Hispanic & Cigar (5/day, 30 years) and alcohol consumption \\
6 & $\checkmark$ & $\checkmark$ & $\checkmark$ & $\checkmark$ & $58 \mathrm{~F}$ & White/Non-Hispanic & Regular alcohol consumption \\
7 & $\checkmark$ & $\checkmark$ & $\checkmark$ & $\checkmark$ & $27 \mathrm{~F}$ & Asian/Pacific Islander & Alcohol consumption $(2 /$ wk) \\
8 & $\checkmark$ & - & - & - & $19 \mathrm{M}$ & White/Non-Hispanic & None \\
9 & $\checkmark$ & $\checkmark$ & $\checkmark$ & $\checkmark$ & $18 \mathrm{~F}$ & White/Non-Hispanic & Prior tobacco and current alcohol consumption \\
10 & $\checkmark$ & $\checkmark$ & $\checkmark$ & $\checkmark$ & $19 \mathrm{~F}$ & Black/Non-Hispanic & Regular alcohol consumption \\
Total & 10 & 7 & 7 & 7 & & & \\
\hline
\end{tabular}

${ }^{a}$ Four specimens

FluoSphere penetration exhibited full-thickness penetration of the oral mucosa epithelium in seven of ten patient explants examined. Contrary to the findings of Axford et al., two of the three negative penetration samples were from patients without an alcohol and/or tobacco history, while all patients with current alcohol and/or tobacco usage exhibited full-thickness penetration (28). 
compatibility and to be metabolized in vitro by alcohol dehydrogenase enzymes $(34,35)$. Furthermore, other feasible compounds, e.g., poly-lactic-co-glycolic acid formulations, are routinely used, well tolerated, and fully functional in the oral cavity (36).

Our data demonstrate, for the first time, that cultured human OSCC cells internalize solid lipid nanoparticles. This ability of SLNs to provide high, sustained intracellular levels of fluorescent probe affords an avenue for both compound stabilization and a mechanism to obtain a local pharmacologic advantage. Relative to free-idarubicin delivery, our data show greater sustained intracellular idarubicin levels following nanoparticle delivery over the extended treatment period. We speculate these data reflect MRP1-mediated free-idarubicin efflux in the OSCG cell lines (37). This speculation was substantiated by the expression of MRP1 in all OSCG cell lines. The lack of BCRP expression in cultured OSCC cells, which contrasts with the presence of BCRP within OSCG tumor nests, is likely attributable to the loss of BCRP during long-term in vitro growth.

A previous study evaluated mRNA levels of multi-drugresistance-related genes [P-gp (mdrl), MRP (unspecified isoform)] in normal human oral tissues (38). In contrast to our findings, which demonstrate that normal oral mucosa contains both BCRP and MRP1 proteins but lacks P-gp, their data show increased mRNA levels of P-gp relative to MRP (38). Because the oral cavity is the point of entry for both the alimentary and pulmonary systems, it is physiologically beneficial to retain detoxification transporters at the epithelial surface-external milieu interface. Furthermore, the highest phase-III levels were observed in the basilar layers of the surface epithelium, which would provide cytoprotection to proliferating basal layer epithelial cells. Relative to the positive control MCF-7 cells, greater levels of phase-III transporters were detected in oral mucosa. These findings likely reflect the constant exposure of oral tissues to foreign compounds. Because the MCF-7 cells were not challenged with xenobiotics, upregulation of phase-III transporters did not occur. The observed lower levels of BCRP and MRP1 in MCF-7 cells relative to normal oral mucosa are consistent with the necessity for detoxification by the respective cell populations.

Furthermore, the presence of MRP1 in the OSCG cell lines appears to have influenced FluoSphere uptake. Our quantitative FluoSphere data show a progressive increase in intracellular levels over time in 2 of the 3 cell lines (i.e., SCC9 and SCC15). Interestingly, the SCC4 cell line, which contains the highest levels of MRP1, exhibits a decrease in FluoSphere concentration from the 6 to $24 \mathrm{~h}$ time points (Fig. 7A and G). This is consistent with the studies conducted by Zhang et al., which showed conjugation of negatively charged nanoparticles to glutathione and subsequent nano- particle efflux from the cell via MRP-transporters (39). Although minimal work has been conducted on SLN and MRP interactions, recent studies show SLN-mediated inhibition of the P-gp efflux pump and depletion of intracellular ATP (20,40). It has also been reported that the MRP1 nanoparticle efflux mechanism can be evaded by maintaining a high concentration of nanoparticles at the treatment site (41). In addition, recent studies suggest COX-2 inhibition down-regulates MRPl and BCRP mRNA in oral cancer cells (42). Notably, our labs recently demonstrated a significant reduction of COX-2 protein concentrations following oral topical application of the anthocyanin-rich FBR gel (11). These collective data imply prolonged local oral SLN delivery of anthocyanins, and fenretinide could circumvent MRP1-mediated efflux (i.e., via concentration gradient maintenance, SLN-mediated inhibition, and anthocyanin, inhibition of COX-2) and achieve therapeutically relevant levels in the target tissues. These data also recapitulate the clinical finding that multiple maintenance doses throughout the day represent the optimal dosing strategy for topical formulations (25).

Oral cancer chemopreventives, which optimally redirect growth of premalignant oral epithelium, require the therapeutic agents to reach the proliferating basal cell epithelial layer. Consequently, while nanoparticle uptake by monolayer epithelial cells is interesting, translational studies should demonstrate nanoparticle penetration of intact, stratified squamous surface epithelium. To date, percutaneous nanoparticle delivery systems have largely been unable to directly penetrate the stratum corneum, but ocular transmucosal nanoparticle delivery systems have shown more success (32,43-45). A recent evaluation of a vitamin A-loaded SLN topical delivery system did, however, successfully exhibit vitamin A penetration across human cadaver skin (46). Despite this finding, their failure to demonstrate direct association of vitamin A diffusion with SLN penetration does not definitively establish the feasibility of a transepidermal topical nanoparticle delivery system (46). Furthermore, although the oral mucosal explant tissues used in our studies were derived from gingival epithelium, which is more keratinized and thicker than the anticipated common sites of oral topical delivery (e.g., floor of mouth, ventral tongue, oral vestibule), the surface epithelium was not as thick and keratinized as epidermis. Also, many of the percutaneous penetration studies were conducted on metabolically inactive porcine skin or cadaver skin following fixation and/or storage at $-20^{\circ} \mathrm{C}$ for up to $2-4$ weeks, which negates the potential for endocytosis $(32,43,46)$. In contrast, the oral mucosal explants used in our study were incubated with nanoparticles within $1 \mathrm{~h}$ of excision from the patients. These characteristics, i.e., presence of viable mucosal tissue combined with the decreased keratinization and epithelial thickness, are likely responsible for the improved efficacy 
and observance of FluoSphere penetration into the basal third and superficial underlying connective tissue in seven of the ten patient explants examined.

These results are particularly promising due to the size of the FluoSpheres (200 nm), a dimension roughly twice the size of the model SLNs, and the negative surface charge of both the SLNs and FluoSpheres. As previously shown by Illum et al., positively charged nanoparticles provide an advantage in mucosal delivery due to their ability to adsorb to the negatively charged mucosal cells $(45,47)$. Therefore, the capacity of normal stratified oral squamous epithelium to allow the penetration and subsequent internalization of negatively charged nanoparticles is particularly promising. Furthermore, the retention of the FluoSpheres in the deep layers of oral epithelium expressing MRP1 and BCRP (Fig. 8C and D) demonstrates the potential to overcome phase-III efflux transporters by maintaining a concentration gradient at the target site. These data introduce the prospect for sustained local oral delivery of poorly water soluble and unstable compounds, e.g., fenretinide, in nanoparticle formulations.

While the objective of this study was to evaluate the feasibility of local oral mucosal delivery with nanoparticle formulations, the observed penetration of nanoparticles through the epithelium and basement membrane into the underlying connective tissue suggests the possibility of oral transmucosal nanoparticle delivery for systemic therapeutics. These nanoparticle findings are consistent with our previous mucosal penetration studies, which showed in vivo systemic uptake of calcitonin and testosterone via buccal transmucosal delivery from mucoadhesive delivery agents $(22,48)$. Collectively, these studies by our laboratories address the main limitations previously reviewed by Madhav et al. of oral transmucosal drug delivery, i.e., stabilization of compounds using nanoparticles and their subsequent loading and release from mucoadhesive bi-layer thin film composites ( $\mathrm{TFG}$ ) intended for unidirectional release to the epithelial cell membrane (27).

These data demonstrate nanoparticle internalization by OSCG cells and support the premise that SLN-based delivery results in higher final intracellular levels relative to bolus administration. Furthermore, the oral mucosal explant data confirm the feasibility of using nanoparticles to deliver chemopreventives to an optimal oral cavity chemoprevention target, i.e., the proliferating, basal layer epithelial cells, but also open the possibility of oral transmucosal nanoparticle delivery for systemic therapeutic applications.

\section{ACKNOWLEDGEMENTS}

This work was supported by the National Institute of Health's National Cancer Institute and National Institute for Dental and Craniofacial Research (R01 CA95901, R21 CA132138 and T32 DE14320) to Susan R. Mallery. This work was also supported, in part, by NIH-NGI R01 CA1 15197 to Russell J. Mumper. The authors also wish to thank Mary Lloyd, Mary Marin, and Deric Budendorf for assisting with tissue processing and collection, Brian Murray for formulation of the thin-film composite, and Drs. Marvin F. Jabero and Courtney A. Jatana for their surgical support.

Open Access This article is distributed under the terms of the Creative Commons Attribution Noncommercial License which permits any noncommercial use, distribution, and reproduction in any medium, provided the original author(s) and source are credited.

\section{REFERENCES}

1. Papadimitrakopoulou VA, Clayman GL, Shin DM, Myers JN, Gillenwater AM, Goepfert $\mathrm{H}$ et al. Biochemoprevention for dysplastic lesions of the upper aerodigestive tract. Arch Otolaryngol Head Neck Surg. 1999;125:1083-9.

2. Lippman SM, Lee JJ, Martin JW, El-Naggar AK, Xu X, Shin DM et al. Fenretinide activity in retinoid-resistant oral leukoplakia. Clin Cancer Res. 2006;12:3109-14.

3. Lippman SM, Batsakis JG, Toth BB, Weber RS, Lee JJ, Martin JW et al. Comparison of low-dose isotretinoin with beta carotene to prevent oral carcinogenesis. N Engl J Med. 1993;328:15-20.

4. Shin DM, Mao L, Papadimitrakopoulou LM, Clayman G, El-Naggar AK, Shin HJC et al. Biochemopreventive therapy for patients with premalignant lesions of the head and neck and p53 gene expression. J Natl Cancer Inst. 2000;92:69-73.

5. William WN, Lee JJ, Lippman SM, Martin JW, Chakravarti N, Tran HT et al. High-dose fenretinide in oral leukoplakia. Cancer Prev Res. 2009;2:22-6.

6. Rudin GM, Cohen EE, Papadimitrakopoulou VA, Silverman S, Recant W, El-Naggar AK et al. An attenuated adenovirus, ONYX015, as mouthwash therapy for premalignant oral dysplasia. J Clin Oncol. 2003;21(24):4546-52.

7. Toma S, Benso S, Albanese E, Palumbo R, Cantoni E, Nicolò G et al. Treatment of oral leukoplakia with beta-carotene. Oncology. 1992;49:77-81.

8. Papdimitrakopoulou VA, William WM, Dannerberg AJ, Lippman SM, Lee JJ, Ondrey FG et al. Pilot randomized phase II study of celecoxib in oral premalignant lesions. Clin Cancer Res. 2008;14:2095-101.

9. Meyskens FL. Another negative chemoprevention trial: what can we learn? Clin Cancer Res. 2008;14:2-3.

10. Shumway BS, Kresty LA, Larsen PE, Zwick JC, Lu B, Fields HW et al. Effects of a topically applied bioadhesive berry gel on loss of heterozygosity indices in premalignant oral lesions. Clin Cancer Res. 2008;14:2421-30.

11. Mallery SR, Zwick JC, Pei P, Tong M, Larsen PE, Shumway BS et al. Topical application of a bioadhesive black raspberry gel modulates gene expression and reduces cyclooxygenase 2 protein in human premalignant oral lesions. Cancer Res. 2008; 68:4945-7.

12. Ugalde GM, Liu Z, Ren C, Chan KK, Rodrigo KA, Yhonghua LY et al. Distribution of anthocyanins delivered from 
a bioadhesive black raspberry gel following topical intraoral application in normal healthy volunteers. Pharm Res. 2009;26 (4):977-86.

13. Kresty LA, Morse MA, Morgan C, Carlton PS, Lu J, Gupta A et al. Chemoprevention of esophageal tumorigenesis by dietary administration of lyophilized black raspberries. Cancer Res. 2001;61:6112-9.

14. Kim HJ, Lotan R. N-(4-Hydroxyphenyl)retinamide-induced apoptosis triggered by reactive oxygen species is mediated by activation of MAPKs in head and neck squamous carcinoma cells. Oncogene. 2006:25:2785-94.

15. Clifford JL, Menter DG, Wang M, Lotan R, Lippman SM. Retinoid receptor-dependent and independent effects of $\mathrm{N}$ (4-Hydroxyphenyl)retinamide in F9 embryonal carcinoma cells. Cancer Res. 1999;59:14-8.

16. Kumari A, Yadav SK, Yadav SC. Biodegradable polymeric nanoparticles based drug delivery systems. Colloids Surf B. 2010; 75:1-18.

17. Rodrigo KA, Rawal Y, Renner RJ, Schwartz SJ, Tian Q, Larsen $\mathrm{PE}$ et al. Suppression of the tumorigenic phenotype in human oral squamous cell carcinoma cells by an ethanol extract derived from freeze-dried black raspberries. Nutr Cancer. 2006;54:58-68.

18. Rinaldi AL, Morse MA, Fields HW, Rothas DA, Pei P, Rodrigo KA et al. Curcumin activates the aryl hydrocarbon receptor yet significantly inhibits (-)-benzo(a)pyrene-7R-trans-7, 8-dihydrodiol bioactivation in oral squamous cell carcinoma cells and oral mucosa. Cancer Res. 2002;62:5451-6.

19. Mallery SR, Shenderova A, Pei P, Begum S, Ciminieri JR, Wilson $\mathrm{RF}$ et al. Effects of 1-hydroxycamptothecin, delivered from locally injectable poly(lactide-co-glycolide) microspheres, in a murine human oral squamous cell carcinoma regression model. Anticancer Res. 2001;21:1713-22.

20. Ma P, Dong X, Swadley CL, Gupte A, Leggas M, Ledebur HC et al. Development of idarubicin and doxorubicin solid lipid nanoparticles to overcome Pgp-mediated multiple drug resistance in leukemia. J Biomed Nanotechnol. 2009;5(2):151-61.

21. Cui Z, Mumper RJ. Bi-layer films for mucosal (genetic) immunization via the buccal route in rabbits. Pharm Res. 2002;19(7):947-53.

22. Cui Z, Mumper RJ. Buccal transmucosal delivery of calcitonin in rabbits using thin-film composites. Pharm Res. 2002;19(12): 1901-6.

23. Bradford MM. A rapid and sensitive method for the quantitation of microgram quantities of protein utilizing the principle of protein-dye binding. Anal Biochem. 1976;72:248-54.

24. Hipfner DR, Almquist KC, Stride BD, Deely RG, Cole SPC. Location of a protease-hypersensitive region in the multidrug resistance protein (MRP) by mapping of the epitope of MRPspecific monoclonal antibody (QCRL-1). Cancer Res. 1996;56: 3307-14.

25. González-Moles MA, Scully C. Vesiculo-erosive oral mucosal disease management with topical corticosteroids: (1) Fundamental principles and specific agents available. J Dent Res. 2005;84:294-301.

26. Li Y, Li LJ, Zhang ST, Wang LJ, Zhang Z, Gao N et al. In vitro and clinical studies of gene therapy with recombinant human adenovirus-p53 injection for oral leukoplakia. Clin Cancer Res. 2009;15(21):6724-31.

27. Satheesh Madhar NV, Shakya AK, Shakya P, Singh K. Orotransmucosal drug delivery systems: a review. J Control Release. 2009;140:2-11

28. Axford SE, Hopwood D. Fluid phase endocytosis within buccal mucosal cells of alcohol misusers. Oral Oncol. 1999;35: 86-92.

29. Hopwood D, Murray FE. Endocytosis of fluorescent microspheres by human oesophageal epithelial cells: comparison between normal and inflamed tissue. Gut. 1995;37:598-602.
30. Innes NPT, Ogden GR. A technique for the study of endocytosis in human oral epithelial cells. Arch Oral Biol. 1999; 44:519-23.

31. Hall W, Ross PE. Fluid phase endocytosis in oral epithelia: variation with site and effect of cancer. J Oral Pathol Med. 2000;29:220-5.

32. Alvarez-Roman R, Naik A, Kalia YN, Guy RH, Fessi H. Skin penetration and distribution of polymeric nanoparticles. J Control Release. 2004;99:53-62.

33. Frohlich E, Kueznik T, Samberger C, Roblegg E, Wrighton C, Pieber TR. Size-dependent effects of nanoparticles on activity of cytochrome P450 isoenzymes. Toxicol Appl Pharmacol. 2010;242 (3):326-32

34. Koziara JM, Oh JJ, Akers WS, Ferraris SP, Mumper RJ. Blood compatibility of cetyl alcohol/polysorbate-based nanoparticles. Pharm Res. 2005;22(11):1821-8.

35. Dong X, Mumper RJ. The metabolism of fatty alcohols in lipid nanoparticles by alcohol dehydrogenase. Drug Dev Ind Pharm. 2006;32(8):973-80.

36. Herberg S, Siedler M, Pippig S, Schuetz A, Dony C, Kim C et al. Development of an injectable composite as a carrier for growth factor-enhanced periodontal regeneration. J Clin Periodontal. 2008;35:976-84.

37. Kruh GD, Belinsky MG. The MRP family of drug efflux pumps. Oncogene. 2003;22:7537-52.

38. Cho YS, Kim MJ. Expression of multidrug resistance-related genes in oral squamous cell carcinomas. Oral Oncol. 2001;37: $652-9$.

39. Zhang Y, Hu Z, Ye M, Pan Y, Chen J, Luo Y et al. Effect of poly (ethylene glycol)-block-polylactide nanoparticles on hepatic cells of mouse: low cytotoxicity, but efflux of the nanoparticles by ATPbinding cassette transporters. Eur J Pharm Biopharm. 2007;66: 268-80

40. Dong X, Mattingly CA, Tseng M, Cho M, Adams VR, Mumper RJ. Doxorubicin and paclitaxel-loaded lipid-based nanoparticles overcome multi-drug resistance by inhibiting P-gp and depleting ATP. Cancer Res. 2009;69(9):3918-26.

41. Panyam J. Dynamics of endocytosis and exocytosis of poly(D, Llactide-co-glycolide) nanoparticles in vascular smooth muscle cells. Pharm Res. 2003;20:212-30.

42. Ko S, Choi GJ, Lee JH, Han YA, Lim S, Kim SH. Differential effects of selective cyclooxygenase-2 inhibitors in inhibiting proliferation and induction of apoptosis in oral squamous cell carcinoma. Oncol Rep. 2008;19:425-33.

43. Wu X, Biatry B, Cazeneuve C, Guy RH. Drug delivery to the skin from sub-micron polymeric particles formulations: influence of particle size and polymer hydrophobicity. Pharm Res. 2009;26 (8):1995-2001.

44. Rancan F, Papakostas D, Hadam S, Hackbarth S, Delair T, Primard $\mathrm{C}$ et al. Investigation of polylactic acid (PLA) nanoparticles as drug delivery systems for local dermatotherapy. Pharm Res. 2009;26(8):2027-36.

45. de Campos AM, Diebold Y, Carvalho ELS, Sanchez A, Alonso MJ. Chitosan nanoparticles as new ocular drug delivery systems: in vitro stability, in vivo fate, and cellular toxicity. Pharm Res. 2004;21 (5):803-10.

46. Pople PV, Singh KK. Development and evaluation of topical formulation containing solid lipid nanoparticles of vitamin A. AAPS PharmSciTech. 2006;7(4):E1-7.

47. Illum L, Jabbal-Gill I, Hinchcliffe M, Fisher AN, Davis SS. Chitosan as a novel nasal delivery system for vaccines. Adv Drug Del Rev. 2001;51(1-3):81-96.

48. Jay S, Fountain W, Cui Z, Mumper RJ. Transmucosal delivery of testosterone in rabbits using novel bi-layer mucoadhesive wax-film composite disks. J Pharm Sci. 2002;91(9):2016-25.

49. Hed J, Hallden G, Johansson SG, Larsson P. The use of fluorescence quenching in flow cytofluorometry to measure the 